倌 a 18 de outubro de 2019 - Campinas | Brasil

\title{
Efeito do clareamento caseiro contendo diferentes espessantes nas propriedades físicas de um nanocompósito livre de bisfenol $A$.
}

\section{Isabele Vieira*, Laura Nobre Ferraz, Débora A. N. L. Lima.}

\section{Resumo}

O objetivo deste estudo foi avaliar a influência do peróxido de carbamida (PC) a 16\% contendo diferentes espessantes sobre as propriedades físicas de uma resina nanocomposta livre de bisfenol A (BPA). Foram confeccionadas 72 amostras de resina composta nanoparticulada (Z350 XT®) e 72 amostras de resina composta nanoparticulada livre de BPA (Vittra APS( $($ ). As amostras foram aleatoriamente divididas em 12 grupos de acordo com cada tipo de resina e com o tratamento clareador/espessante $(n=12)$ : sem tratamento (Controle), aplicação de gel comercial de peróxido de carbamida a $16 \%$ com o espessante carbopol, aplicação de gel manipulado de peróxido de carbamida a 16\% com o espessante carbopol, aplicação de gel manipulado de peróxido de carbamida a 16\% com o espessante natrosol, aplicação de carbopol e aplicação de natrosol. O tratamento clareador foi realizado por 4 horas, durante 14 dias. Foram realizadas as análises de $\operatorname{cor}(\Delta \mathrm{E})$, rugosidade média $(\mathrm{Ra})$ e microdureza Knoop $(\mathrm{KHN})$. Os dados foram submetidos a análise de ANOVA e teste de Tukey. Os maiores valores de rugosidade foram observados no grupos da Z350 XT® clareado com gel de peróxido de carbamida a 16\% com natrosol e o grupo da Vittra APS $®$ com aplicação de gel de natrosol. Para a cor não houve diferença estatística significante para os grupos da Z350 XT®, já para a Vittra APS® o grupo com aplicação de carbopol apresentou os menores valores de $\Delta \mathrm{E}$. Para a microdureza, o grupo Z350 XT® clareado com gel manipulado de peróxido de carbamida a $16 \%$ com carbopol apresentou os menores valores. Mudanças nas propriedades físicas da resina nanocomposta livre de bisfenol A (BPA) por agentes clareadores variam dependendo do espessante utilizado.

\section{Palavras-chave:}

Clareamento dental, nanocompósito, natrosol, carbamida.

\section{Introdução}

A aplicação de gel clareador sobre restaurações pode resultar em possíveis alterações da resina composta como o aumento da rugosidade, a diminuição da dureza, mudanças de cor e opacidade. $1^{1-3}$ Essas alterações podem variar de acordo com a composição da resina composta, composição do gel, frequência e duração do tratamento clareador. ${ }^{4}$

O polímero carboxipolimetileno (carbopol) é o espessante mais utilizado na composição dos géis clareadores caseiros, porém tem sido associado a alterações nas propriedades físicas da resina composta, como a redução na dureza do material. ${ }^{5} \mathrm{O}$ natrosol é um espessante amplamente utilizado na indústria cosmética e seu uso tem sido proposto na composição de produtos clareadores. ${ }^{6}$

Em relação às resinas compostas, a sua fase orgânica é constituída por componentes derivados do bisfenol $A$ (BPA). Estudos in vitro têm mostrado que o BPA é estrogênico, ${ }^{7}$ assim, recentemente, foi lançado no mercado uma resina composta nanoparticulada livre de BPA. A sua matriz monomérica contém monômeros tipo UDMA e TEGDMA. Sua carga é composta por nanoesferas $(100-200 \mathrm{~nm})$ de um complexo de Silica-Zircônia que podem conferir ao compósito melhor desempenho mecânico, maior resistência ao desgaste, melhor brilho e polimento.

Assim, o objetivo desse estudo foi avaliar o efeito do clareamento caseiro à base de peróxido de carbamida $16 \%$ com diferentes espessantes sobre a mudança de cor, rugosidade e microdureza de uma resina composta livre de BPA. os maiores valores de rugosidade entre todos os grupos e não diferiram estatisticamente entre si.

Para a microdureza, todos os grupos da Z350XT® com aplicação de gel diferiram estatisticamente do grupo controle, sendo que o grupo clareado com gel manipulado de peróxido de carbamida a 16\% com carbopol apresentou os menores valores de microdureza. Já para a Vittra APS $\AA^{\circ}$ não houve diferença estatística entre os grupos não diferindo do grupo controle. $\mathrm{Na}$ análise de cor, não houve diferença estatística significante para os grupos da Z350 XT®, já para a Vittra APS® o grupo com aplicação de carbopol apresentou os menores valores de $\Delta \mathrm{E}$, diferindo estatisticamente dos outros grupos.

\section{Conclusões}

Mudanças nas propriedades físicas da resina nanocomposta livre de bisfenol A (BPA) por agentes clareadores variam dependendo do espessante utilizado.

\section{Agradecimentos}

Ao PIBIC pela concessão da bolsa.

${ }^{1}$ Hafez R, Ahmed D, Yousry M, El-Badrawy W, El-Mowafy O. Effect of in-office bleaching on color an surface roughness of composite restoratives. Eur J Dent. 2010; 4:118-27.

${ }^{2}$ Torres CR, Ribeiro CF, Bresciani E, Borges AB. Influence of hydrogen peroxide bleaching gels on color, opacity, and fluorescence of composite resins. Oper Dent. 2012; 37:526-31

${ }^{3}$ De Andrade IC, Basting RT, Rodrigues JA, do Amaral FL, Turssi CP. Franç FM. Micro hardness and color monitoring of Nano filled resin composite after bleaching and staining. Eur J Dent. 2014; 8:160-5.

${ }^{4}$ Attin T, Hannig C, Wiegand A, Attin R. Effect of bleaching on restorative materials and restorations-a systematic review. Dent Mater. 2004; 20:852-861.

${ }^{5}$ Lima DA, De Alexandre RS, Martins AC, Aguiar FH, Ambrosano GM, Lovadino JR. Effect of curing lights and bleaching agents on physical properties of a hybrid composite resin. J Esthet Restor Dent 2008; 20:26673.

${ }^{6}$ Gouveia TH, Públio Jdo C, Ambrosano GM, Paulillo LA, Aguiar FH, Lima DA. Effect of at-home bleaching with different thickeners and aging on physical properties of a nanocomposite. Eur J Dent. 2016 JanMar;10(1):82-91. doi: 10.4103/1305-7456.175683.

${ }^{7}$ Fleisch AF, Sheffield PE, Chinn C, Edelstein BL, Landrigan PJ. Bisphenol A and related compounds in dental materials. Pediatrics. 2010 Oct;126(4):760-8. doi:10.1542/peds.2009-2693.

\section{Resultados e Discussão}

$\mathrm{Na}$ análise de rugosidade de superfície, o grupo da Z350 $\mathrm{XT} \circledast$ clareado com gel manipulado de peróxido de carbamida a $16 \%$ com o espessante natrosol e o grupo da Vittra APS $\AA^{\circ}$ com aplicação de gel de natrosol apresentaram 